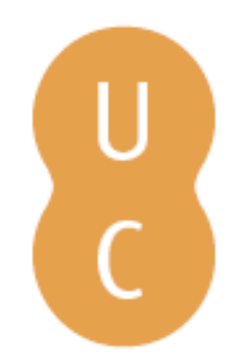

\title{
pommalina
}

\section{O ensino das ciências no curso filosófico criado pelos estatutos pombalinos da universidade de Coimbra}

\author{
Autor(es): $\quad$ Costa, A. M. Amorim da \\ Publicado por: Imprensa da Universidade de Coimbra \\ URL \\ persistente: URI:http://hdl.handle.net/10316.2/32269 \\ DOI: $\quad$ DOI:http://dx.doi.org/10.14195/978-989-26-0413-8_4 \\ Accessed : $\quad$ 26-Apr-2023 15:47:27
}

A navegação consulta e descarregamento dos títulos inseridos nas Bibliotecas Digitais UC Digitalis, UC Pombalina e UC Impactum, pressupõem a aceitação plena e sem reservas dos Termos e Condições de Uso destas Bibliotecas Digitais, disponíveis em https://digitalis.uc.pt/pt-pt/termos.

Conforme exposto nos referidos Termos e Condições de Uso, o descarregamento de títulos de acesso restrito requer uma licença válida de autorização devendo o utilizador aceder ao(s) documento(s) a partir de um endereço de IP da instituição detentora da supramencionada licença.

Ao utilizador é apenas permitido o descarregamento para uso pessoal, pelo que o emprego do(s) título(s) descarregado(s) para outro fim, designadamente comercial, carece de autorização do respetivo autor ou editor da obra.

Na medida em que todas as obras da UC Digitalis se encontram protegidas pelo Código do Direito de Autor e Direitos Conexos e demais legislação aplicável, toda a cópia, parcial ou total, deste documento, nos casos em que é legalmente admitida, deverá conter ou fazer-se acompanhar por este aviso.

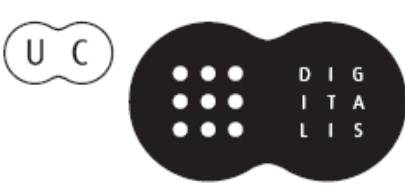


João Rui Pita

Coordenaçáo

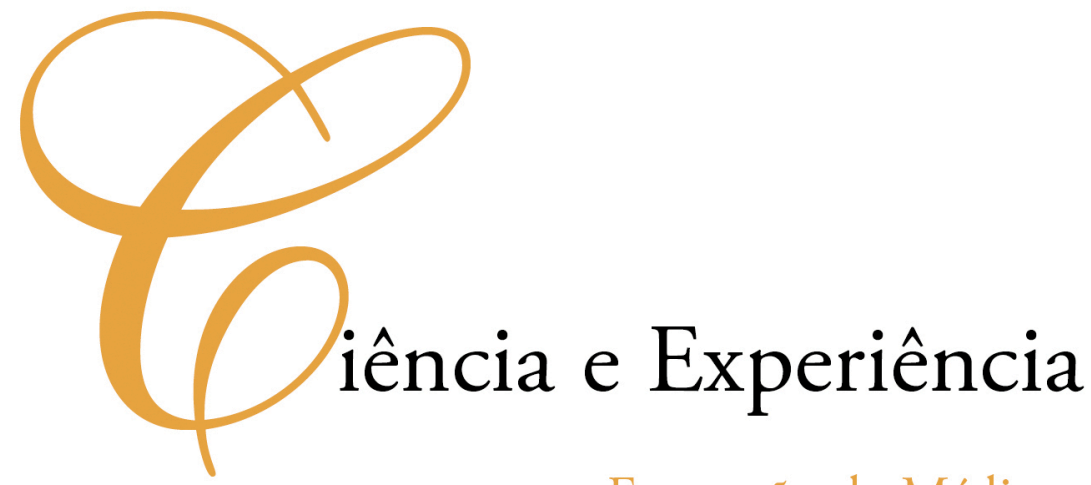

Formação de Médicos, Boticários, Naturalistas e Matemáticos

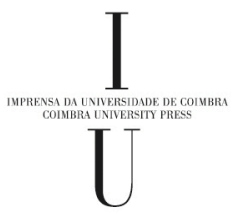

- COIMBRA 2006 


\section{A. M. Amorim da Costa}

\section{O ENSINO DAS CIÊNCIAS NO CURSO FILOSÓFICO CRIADO PELOS ESTATUTOS POMBALINOS DA UNIVERSIDADE DE COIMBRA}

\section{Introdução}

Às Universidades se pede que ensinem a juventude que as frequenta; produzam obras que enriqueçam o património da ciência; e orientem a opinião pública nas questões mais árduas que ponham em jogo os interesses das nações ${ }^{(1)}$.

Em Portugal, a consideração do desenvolvimento económico e social do país ao longo da Idade Moderna, particularmente do século XVII até hoje, deixa-nos um sentimento geral de que a Universidade Portuguesa, na maior parte do tempo da sua existência, tem falhado no cumprimento da tripla missão que acabámos de referir. De facto, não é de todo líquido que ela se venha afirmando seja pelo carácter criador e de excelência do ensino que ministra, seja pela originalidade das obras que nela se publicam, seja, ainda, pelo exercício de arbitragem de reconhecimento incontestado de supremo árbrito da opinião nacional.

Todos conhecemos, as contínuas queixas que dos mais diversos sectores sociais contra ela se fazem, assacando-lhes fundadas e não alijáveis culpas

\footnotetext{
(1) Diogo Pacheco de Amorim, Da Cultura Geral do Universitário, Coimbra, Ed. Atlântida, 1951, p. 15.
} 
do atraso e desorganização em que o país vai vivendo, década após década. Ciclicamente, os mentores da Universidade Portuguesa reclamam a sua reforma, mesmo com uma frequência muito maior do que aquela que seria prudente e sabiamente aconselhável, caso houvesse real interesse em avaliar correctamente todas as virtualidades de reformas anteriores, e não incontida tendência para continuamente se pôr em causa tudo o que está em vigor, a que subjaz, tantas vezes, um sentimento narcisístico de deixar o próprio nome ligado a um projecto inovador, aceitando com relutância enquadrar-se em projectos que são de outros, mesmo antes de conhecer e examinar todas as sua potencialidades. Almejando a novidade, falta-nos frequentemente a pertinácia para nos preocuparmos com uma avaliação minimamente desapaixonada do que já foi ou está a ser feito.

Ciclicamente, também, dentro e fora da Universidade, se afirma a ineficácia do ensino que existe, bem como o seu isolamento relativamente ao país ao serviço do qual deveria estar a todo o momento e ainda a sua improdutividade científica. E tudo, fundamentalmente, porque, de um modo ou outro, se considera genericamente que a Universidade Portuguesa não prepara o aluno para ser criativo e persistente, ficando-se facilmente por uma repetição do saber já criado. Como noutro local já o afirmámos, sem pertinácia no trabalho encetado, não é possível qualquer observação demorada; não é possível a obra colectiva em que se configura a criação de ciência; não se realiza a criação de saber; fica-se por uma investigação inteiramente marcada pelo cariz individual, motivada, na maioria dos casos, pela progressão académica. É o domínio do academismo e do isolamento.

Tendencialmente, mais dominados pela paixão do que pela razão, nós portugueses, na nossa formação académica descuramos frequentemente uma atitude correcta de indagação e procura sistemática dos quês e porquês, redundando numa formação altamente prejudicada, à partida, e prejudicada, ainda, pelo facto de nos faltar, por temperamento, pertinácia bastante e concentração suficiente para lidar até onde seja necessário e possível, com os problemas que não obstante as deficiências do sistema educativo, tenham, porventura, sido algum dia por nós equacionados. 
O espírito científico decorrente da revolução científica dos séculos XVI-XVII não se compadece com este tipo de formação. Porque ela perdurou e perdura na Universidade Portuguesa, não surpreende que o ensino que nela se ministra seja periodicamente contestado, acusado de ser ineficaz, assacando-se-lhe, como já acima o dissemos, as grandes culpas do atraso e desorganização do país e justificando o proverbial atraso científico dos povos ibéricos. ${ }^{(2)}$

Este tipo de contestação conheceu um dos mais significativos picos na primeira metade do século XVIII com muitas figuras de proa, com destaque para os chamados "estrangeirados", sendo de justiça realçar as figuras de Luis António Verney (1713-1792) e António Ribeiro Sanches (1699-1783). Nela germinou e a partir dela se fez a Reforma Pombalina da Universidade Portuguesa, com incidência específica no ensino das ciências distribuído pelas Faculdades de Matemática, Medicina e Filosofia.

\section{A formação científica nos Estatutos do Curso Filosófico da Reforma Pombalina}

Servindo-nos duma afirmação de Gomes Teixeira, podemos dizer que os Estatutos Pombalinos (1772) não são um simples código de preceitos a seguir nas diversas Faculdades da Universidade de Coimbra, como o são ordinariamente os documentos desta natureza, mas são, sim, uma dissertação notável sobre o ensino das ciências, repleta de sã pedagogia e elevada filosofia, em linguagem vernácula e elegante, onde todas as disposições são nitidamente explicadas e justificadas, com conselhos preciosos aos alunos e preceitos salutares aos mestres ${ }^{(3)}$. Aqui procuraremos explicitar as linhas mestras dessa "Sã pedagogia e elevada filosofia» no que ao ensino das ciências se refere.

(2) A. M. Amorim da Costa, Academismo e Insularidade no Desenvolvimento da Química Portuguesa no Século XIX e Princípios do século XX in Ciência e Progresso, Décimo Encontro de Filosofia, Coimbra, APF, 1996, pp.89-117

(3) F. Gomes Teixeira in Diogo Pacheco de Amorim, O. Cit., Prefácio, p. 12. 
E muito embora os Estatutos Pombalinos distribuam os estudos científicos, a saber, o estudo das ciências naturais e filosóficas, em contraposição aos estudos teológicos e jurídicos, por três cursos designados por Curso Médico $^{(4)}$, Curso Matemático(5) e Curso Filosófico(6), a cada um dos quais se fez corresponder as acima mencionadas Faculdades de Medicina, Matemática e Filosofia, cada qual com o seu Estatuto próprio, restringiremos a nossa análise ao Curso Filosófico, referindo-nos, consequentemente, apenas à pedagogia e filosofia que informa o preceituado na Terceira Parte do Livro III dos referidos Estatutos, os estatutos do Curso Filosófico.

Com os seus Estudantes divididos em duas Classes, os Estudantes Obrigados e os Estudantes Ordinários, o Curso Filosófico deveria ordenar-se de tal sorte a preparar os primeiros - os estudantes destinados ao curso de medicina e ao curso de matemática - para entrarem com fruto nos cursos a que se destinaram; e os segundos — os estudantes que se destinavam a estudar a Filosofia por si mesma, para serem Filósofos de profissão - para que incorporados numa Faculdade ou simplesmente interessados no estudo para sua instrução pudessem promover e adiantar o avanço da ciência ao serviço do progresso da sociedade.

Porque a "miserável Faculdade» até então incorporada na Universidade com o nome de Faculdade das Artes «tão longe esteve de satisfazer a estes importantes objectos, que muito pelo contrário foi a origem, e raiz venenosa, donde nasceu a escura, pueril e sofisticada loquacidade, que invadio, e corrompeo todos os Ramos do Ensino público», a merlhor solução encontrada foi abolir por completo a dita Faculdade, "como sistema incorrigível e indigno da Reforma» e criar em seu lugar uma totalmente nova. Nada de vinho novo em odres velhos, nem remendo novo em pano velho que isso são práticas de deitar tudo a perder, como doutamente nos avisa a sabedoria evangélica. Regulada por cânones que se queriam totalmente novos

\footnotetext{
(4) Estatutos Pombalinos da Universidade de Coimbra, Liv. III, Pt. I. Tits. I-VII.

(5) Idem, Liv. III, Pt. II, Tits. I-VIII.

(6) Idem, Liv. III, pt. III, Tits. I-VIII.
} 
que eficazmente permitissem produzir os bons efeitos que se desejavam, que mais se não empregasse em falar, mas em saber, e «sendo manifesto que a filosofia he a alma de todos os conhecimentos humanos», o nome surgia com naturalidade — Faculdade de Filosofia, uma Faculdade a ser «reputada e havida por uma Classe maior do Ensino público, em tudo igual, estatutariamente, às outras Faculdades»(7).

\subsection{Empregar-se em saber, não em falar}

Destes considerandos constituintes decorre o primeiro princípio básico da pedagogia e filosofia desta nova Faculdade: empregar-se em saber, não em falar. Saber é conhecer os factos e fenómenos por imediata observação, que a Natureza oferece aos olhos dos homens no curso ordinário das suas operações, e também aquelas verdades que somente se podem haver por meio da Experiência, a qual obriga a mesma Natureza a declarar as verdades mais escondidas, que por si mesma não quer manifestar, senão sendo perguntada com muita destreza e artifício.

Este princípio consagra a orientação experimentalista de todo o articulado dos Estatutos Pombalinos no que se refere à estrutura e conteúdo do Curso Filosófico e claramente se filia no valor do experimentalismo defendido por Luis António Verney no seu Verdadeiro Método de Estudar, voltado, ao mesmo tempo, contra os peripatéticos e contra os cartesianos que "não se querem abaixar às experiências acompanhadas do raciocínio (...). Pasma um homem de ver a facilidade com que explicam qualquer fenómeno que se oferece. Fala V. P. do Raio, e respondem-lhe que se compõe de matéria, forma e privação. (...) E que se chamem filósofos estes tais! E que condenem os que observam miudamente a natureza»(8).

\footnotetext{
(7) Idem, Liv. III, Pt III, ns. 4-6.

(8) Luis António Verney, Verdadeiro Método de Estudar (1746), Ed. Salgado Junior, Sá da Costa, Lisboa, 1950, vol. 3º, pp. 179-180.
} 
Todavia, a base experimentalista do saber que o bom filósofo deve cultivar não é incompatível com a Filosofia Racional e Moral que com a Filosofia Natural constituem as três partes da verdadeira Filosofia. De facto, a Filosofia Racional e Moral devem servir de entrada e frontispício ao Curso Filosófico. É que, sendo todas as verdades que nele se devem ensinar, primeiros princípios que necessitam de discussão e combinação para se alcançarem e provarem, necessário é conhecer as regras pelas quais se deve fazer a combinação e o caminho por onde há-de passar continuamente o entendimento do conhecido para o desconhecido. Impõe-se, todavia, que ela se limite às regras fundamentais e necessárias sem se deixar perder na vasta floresta de preceitos inúteis e questões extravagantes que os Escolásticos cultivaram, fazendo longa, difícil e embaraçada a arte de discorrer que deve ser breve, fácil e expedita.

É nesta perspectiva que o Curso Filosófico com a duração de quatro anos, com uma cadeira por ano, compreendia no seu curriculum, logo no primeiro ano, a Filosofia Racional e Moral, abrangendo as Regras necessárias da Lógia e a praxe delas nos três primeiros meses, seguindo-se-lhe a Metafísica (compreendendo a ontologia, a pneumatologia e a psicologia), a ser tratada como a "primeira Sciência da Razão", que explica como o Entendimento deve passar das ideias havidas pelas impressões dos sentidos às ideias abstractas e gerais, expurgada das «subtilezas frívolas e delírios insensatos dos peripatéticos», mostrando como por huma combinação e indução seguida, e uniforme, se chega a estabelecer certos Principios e verdades comuns a todos os Homens. No seu estudo, expressamente deveriam ser deixadas de fora «o grande número de questões escuras, e inaveriguáveis, que tem excitado a presunção vaidosa de disputar tudo, e sem "perder o tempo em pertender provar aquella classe de verdades, que não são de discussão, mas de sentimento», limitando-se «a fazer huma Collecção das verdades, e conhecimentos certos, que podemos adquirir pela meditação e reflexão sobre as operações da mesma Alma, que são os factos, por experiências». 
E acabada a Metafísica, passar-se-ia à exposição dos princípios da Moral, no entendimento de que «esta Sciencia não deve ser tanto disputada, como praticada» $(9)$.

A preocupação é constante: fugir do verbalismo estéril, da discussão improfícua, do discurso débil e meramente especulativo, com que a eficácia do verdadeiro saber e conhecimento da Natureza se não compadece.

\subsection{O carácter prático e utilitário do conhecimento da Natureza}

O programa e metodologia delineados para as cadeiras dos três anos seguintes do Curso, a História Natural (2 ano), a Física Experimental ( $3^{\circ}$ ano) e a Chimica ( $4^{\circ}$ ano), são bem explícitos quanto ao requisitos de eficácia do saber que sirva o progresso da sociedade, como princípio primordial da actividade do espírito humano. Podemos, pois, acrescentar ao empregar-se em saber, não em falar da pedagogia e filosofia dos Estatutos Pombalinos para o Curso Filosófico, a afirmação clara e decidida do carácter prático e utilitário do conhecimento da Natureza para o sempre desejado progresso económico e social do país.

No ensino da História Natural devia o lente «fazer huma descripção exacta de cada hum dos productos da Natureza», segundo a divisão dos seus três reinos, o Animal, o Vegetal e o Mineral, coligindo todos os factos e observações que sobre eles se tem feito, com uma ideia justa da sua confirmação e combinação, de modo a generalizá-los e ligá-los reciprocamente por um encadeamento de analogias até chegar àquele grau superior de conhecimentos que se requer para explicar os factos particulares pelos gerais e

(9) Estatutos Pombalinos da Universidade de Coimbra, Liv. III, Pt. III, Tit. III, cp. I. Nota: Em 1791, na primeira reforma curricular do Curso Philosophico, por carta régia de 24 de Janeiro, a cadeira de Filosofia Racional e Moral seria substituída por uma cadeira de Botânica e Agricultura. 
comparar a Natureza consigo mesma nas suas grandes operações, de modo a abrir caminho para aperfeiçoar os diferentes ramos da Física e das artes que delas dependem. Para eficazmente o fazer, o lente não poderia prescindir da redução da multidão dos produtos a "hum Systema methodico, por classes, ordens generos e especies»; todavia, na sistematização necessária não deveria nunca ir além do estritamente necessário, "sendo manifesto que a Sciencia teria feito maiores pregressos, se tivesse havido tanto estudo na observação, como na construcção, e delineamento dos Systemas» "no qual tem havido algum escesso dos Botanicos». Nunca deveria esquecer que o importante no fundo próprio desta ciência é «a história dos usos, e prestimos, que pela observação se em descuberto nas diferentes espécies de Plantas, (Animaes e Mineraes), que a Natureza produz copiosamente para o uso do Homem", relativamente às artes e em tudo em que interessam à Sociedade, «demorando-se sempre no útil e passando em breve resumo o curioso».

Do carácter prático desejado para o ensino da Histórial Natural decorre todo o articulado dos Estatutos que se refere à criação do Gabinete de História Natural e do Jardim Botânico, o primeiro para a "Colecção dos Productos, que pertencem aos tres Reinos da Natureza» e o segundo como "hum Jardim no qual se mostrem as Plantas vivas». Neles, deveria o lente fazer a demonstração todas as vezes que fosse necessário para que, procedendo em tudo com zelo que convém para formar os discipulos solidamente nesta ciência, os tornasse capazes de a promoverem eficazmente por meio da observação(10).

Neste particular referente ao carácter prático e aplicado do ensino ministrado nas cadeiras do Curso Filosófico, o preceituado para o ensino da Física Experimental, a cadeira do terceiro ano, e da Química, a cadeira do quarto ano, repete o que fica observado relativamente ao ensino da História Natural, ainda com maior ênfase, rigorosamente enquadrado pelos mais

(10) Idem, Liv. III, Tit. III, cp. II e Tit. VI, cps. I-II. 
básicos princípios do empirismo racional decorrente da filosofia F. Bacon. Metodologicamente, é prescrito que o lente instrua os seus discípulos na «idea geral da sagacidade, e attenções, que se devem applicar na Arte de fazer Experiencias; como se hão de repetir, e combinar; como se hão de distinguir os factos acessorios; dos principaes; como se hão de distribuir os effeitos complicados de huma Experiencia, por meio de outras experiencias parciaes, que excluam sucessivamente as circunstancias da primeira; e como se deve fazer uso da Razão; para se conjecturar o effeito antes de o experimentar, e para se escolherem as circunstancias, em que se devem fazer experiencias decisivas, e izentas de toda a equivocação».

A propósito do ensino da Física, expressamente se declara que «se limite o estudo do Filosofo à simples collecção das verdades decisivamente provadas por via de facto; abstendo-se de imaginar hypotheses, e de fabricar Systemas gratuitos, que tem sido na Filosofia o mesmo que a fábula na História». E expressamente se abjura o cartesianismo(11) pedindo ao Professor cautela "para não cahir naquelle furor de explicar tudo, que Descartes introduzio na Fysica; costumando os seus Sectarios a contentar-se com Principios, e razoes vagas, proprias a defender igualmente o pro, e o contra; como se ve em muitos Authores Modernos, os quaes explicam as variações do Barometro; a formação da neve; e huma infinidade de outros Fenomenos de hum modo tão froxo, e tão vago, que pelas mesmas palavras se poderiam explicar, quando elles fossem absolutamente contrarios ao que mostra Experiencia».

Nesta cadeira, estudando a natureza, propriedades e fenómenos particulares dos Corpos Fluidos, o Ar, a Agua, a Luz, o Magnetismo e a Electricidade, deveria o lente «recolher e ajuntar todas as verdades de facto que decisivamente se provassem pelas Experiencias (...) bem discutidas e combinadas»,

(11) É pública a aversão que o Marquês de Pombal nutria por Descartes, não devendo esquecer-se o facto de ter mandado queimar as obras deste filósofo que localizou em casa de particulares. 
tendo «O cuidado de dar aos seus Discipulos a idéa intuitiva das mesmas Experiencias», "fazendo as Lições na Casa das Maquinas, todas as vezes, que for necessario" e "procurando que os Discipulos não sejam méros Espectadores; mas que trabalhem, e façam por si mesmos as Experiencias; como he necessario para adquirirem o habito, e sagacidade, que ellas requerem; e para se formarem no gosto de observar a Natureza»(12).

Para que as Lições de Fisica se fizessem com o proveito prescrito pelos Estatutos do Curso Filosófico, se criou de imediato, na Universidade, o Gabinete de Fysica Experimental, "huma Colecção de Maquinas, Aparelhos, e Instrumentos necessaruios para o dito fim»(13).

No ensino da Chimica deveria o Professor explicar «tudo o que tem resultado da combinação das Experiências Chymicas» relativas aos principios e elementos dos Corpos, «sem pertender com tudo averiguar a natureza de cada hum dos elementos simplices, de que os Corpos se compõem; substituindo as imaginações, onde faltam as Experiencias». Tendo explicado os Principios gerais e caracterizado as substâncias metalicas e oleosas, em geral e em particular, completaria o lente o seu programa teórico com a explicação da "Taboa das Affinidades, em que se acham artificiosamente recapituladas as verdades fundamentaes da Arte, que no Curso das Lições se mostram pelo resultado das Experiencias. Não dissimulará porém os defeitos, e imperfeições, que nellas se acham até o presente. Antes mostrará (se possivel for) os meios de a fazer cada vez mais perfeita, e completan.

Todavia, o ensino da disciplina estava longe de se esgotar no cumprimento do programa teórico, que as «lições Theoréticas nesta Sciencia não podem ser bem comprehendidas, sem a prática dellas». O Professor devia pois, "mostrar aos seus Discipulos todos os Processos Chymicos, que são conhecidos na Arte: Tratando da Analyse, e das Operações sobre os diffe-

(12) Estatutos Pombalinos da Universidade de Coimbra, Liv. III, Pt. III, Tit. III, cp. III.

(13) Idem, Liv. III, Pt. III, Tit. VI, cp. III. 
rentes productos dos tres Reinos da Natureza: Não se limitando à escolha dos Processos relativos ao uso de alguma Arte particular: E extendendo a vista sobre todas as que dependem da Chymica geral, e Filosofica». Para isso daria as Lições competentes de Prática no Laboratorio; "nas quaes não fará dos seus Discipulos meros espectadores; mas sim os obrigará a trabalhar nas mesmas Experiencias, para se formarem no gosto de observar a Natureza; e de contribuirem por si mesmos ao adiantamento, e progresso desta Sciencia, a qual não se enriquece com Systemas vãos, e especulações ociosas, mas com descubrimentos reaes, que não se acham de outro modo, senão observando, experimentando, e trabalhando»(14).

Para o efeito, pedia o Estabelecimento do Curso Filosofico, que houvesse na Universidade um Laboratorio no qual se fizessem as Experiencias relativas ao Curso das Lições e onde trabalhasse assiduamente em fazer as preparações que pertencem ao uso das Artes, em geral e da Medicina, em particular(15). O estabelecimento deste Laboratório não foi minimamente descurado; pelo contrário, em curto espaço de tempo se levantou nos terrenos do Colégio dos Jesuitas incorporado no perpétuo domínio da Universidade um amplo edifício devidamente concebido e construído para ser Laboratório de Química, segundo traça do melhor que se conhecia em terras germânicas por se ter concluído ser «o país da Alemanha aquelle em que a referida Arte tem chegado ao grao de maior perfeição»(16).

E o lente era "obrigado a dar por si mesmo aos seus discipulos exemplo do trabalho, e constancia, que se requerem no Observatorio da Natureza: desabusando-os das idéas insensatas dos Escolasticos, que punham a sua gloria em fabricar mundos quiméricos no vasio das suas imaginações»(17).

(14) Idem, Liv. III, Pt. III, Tit. III, cp. IV.

(15) Idem, Liv. III, Pt. III, Tit. VI, cp. IV.

(16) Carta de 12 de Fevereiro do Marquês de Pombal ao Reitor-Reformador in Colecção Geral das Ordens, fl. 92.

(17) Estatutos Pombalinos da Universidade de Coimbra, Liv. III, Pt. III, Tit. III, cp. IV, n. 13. 


\subsection{A história duma ciência no seu ensino}

Para terminar, queremos aqui realçar ainda, um terceiro princípio que informa a pedagogia e filosofia dos Estatutos Pombalinos do Curso Filosófico, o interesse que deve ser dado à história duma ciência no seu ensino.

Todos sabemos que a história das ciências da natureza não tem a mesma função na formação de um cientista que a da história da filosofia ou da teologia na formação de um filósofo ou de um teólogo. De facto, enquanto no desenvolvimento do pensamento filosófico e do pensamento teológico os diversos sistemas desenvolvidos ao longo dos tempos valem pelos postulados em que assentam, podendo por isso nunca perder a sua validade histórica, ou, na pior das hipóteses, a sua actualidade lógica, na história das ciências da Natureza, as teorias de outrora, em geral, não têm qualquer valor enquanto históricas: se continuam actuais, encontram-se incorporadas (ainda que por vezes, não satisfatoriamente enquadradas) nos manuais correntes, sem que se torne necessário qualquer tratado histórico para que se tornem conhecidas; se perderam actualidade, do ponto de vista estritamente científico, deixam de ter qualquer interesse. Por trás desta posição, está a consideração da história da ciência como simples enumeração do passado, uma visão que todos gostaríamos de ver totalmente ultrapassada por quantos vivem e fazem a ciência, conscientes da sua função propedêutica de interpretação e juizo, de anti-dogmatismo e anti-idolatrismo, fundamentadora prática do próprio saber ${ }^{(18)}$.

Inseridos na prática corrente dos séculos XVI-XVII, que só a partir do século XIX passaria a ser objecto de contestação e disputa, os Estatutos Pombalinos do Curso Filosófico prescrevem para o ensino de cada uma das quatro cadeiras que as primeiras lições sejam dedicadas a fazer os Prolegómenos necessários sobre a origem e progresso dela, com «hum resumo

(18) A. M. Amorim da Costa, Introdução à História e Filosofia das Ciências, Lisboa, Publ. Europa-América, col. Saber, 1986, pp. 15-21. 
abbreviado da História della: mostrando a origem que teve; os progressos que fez; as revoluções; os sucessos; a decadência; e o descrédito» por que tenha passado, para melhor compreender o seu estado actual e «as utilidades que tem produzido e que della dependem». Conhecer o passado para melhor compreender o presente e mais eficazmente construir o futuro, podia ser o lema.

\section{Conclusão}

Como dizia D. Francisco de Lemos na sua Relação Geral do Estado da Universidade elaborada em 1777 para ser presente à Rainha D. Maria I como balanço da Reforma Pombalina, do perfeito Estabelecimento das Ciências Naturais nos termos práticos e aplicados prescritos pelos Estatutos se esperava que nestes Reinos e Senhorios de Sua Majestade se iriam manifestar as riquezas que neles depositou a Natureza e logo a indústria teria ampla matéria em que se exercitasse; logo se formariam novos Ramos do Comércio, nasceriam Novas Artes, Novas Manufacturas e Novas Fabricas e se aperfeiçoariam as já existentes; enfim, logo se adiantariam e enriqueceriam estas Ciências de novos Conhecimentos tão necessários para a conservação e usos da Vida Humana e para a felicidade e Gloria da Nação Portuguesa. A experiência das outras Nações da Europa não deixaria duvidar do sucesso que se esperava do referido estabelecimento ${ }^{(19)}$.

A História mostra-nos, porém, que o sucesso, se o houve, foi fugaz e ficou muito aquém do que era esperado.

Hoje, como no tempo da Reforma Pombalina, a tríplice missão da Universidade - preparação profissional, investigação científica e ensino cultural — não se nos afigura ser cumprida em mínimos satisfatórios. A arrumação

\footnotetext{
(19) Francisco de Lemos, Relação Geral do Estado da Universidade, Universidade de Coimbra, 1777 , fls. 122-123.
} 
dos estudos do Curso Filosófico, repartidos hoje pelos múltiplos cursos duma Faculdade de Ciências, e que vai ao ponto de a si ter chamado as matérias do Curso Matemático de então, está longe de encontrar enquadramento próprio no articulado dos Estatutos Pombalinos. A cadeira de Filosofia Racional e Moral deixou por completo de fazer parte dos curricula da Faculdade de Filosofia, mesmo muito antes de esta se ter transformado na Faculdade de Ciências que a veio substituir. A História Natural, a Física Experimental e a Química de cadeiras gerais tornaram-se áreas científicas, com o seu saber distribuído por número cada vez maior de disciplinas, com contributo muito diferente nos curricula dos diversos cursos que foram sendo criados. Os trabalhos práticos de qualquer destas disciplinas não conseguiram acompanhar a sua diferenciação e divisão noutros cursos, com um desenvolvimento e intensidade para os quais os laboratórios estavam mal preparados. Pese embora o redobrado esforço tantas vezes encetado para pôr cobro ao desajustamento crescente entre a missão que o ensino das ciências na Universidade é chamado a cumprir e os meios que são postos à sua disposição para a levar a efeito, parece-nos poder dizer que na Universidade que hoje temos estamos em piores condições para satisfazer cabalmente a sua missão do que o estava a Universidade reformada em 1772, regulada pelos Estatutos Pombalinos.

A deterioração verificada incide fundamentalmente sobre o carácter prático e aplicado do ensino que temos, e o carácter passivo do aluno no processo de aprendizagem, duas das características básicas do ensino prescrito para o Curso Filosófico pelos Estatutos do Marquês de Pombal. De facto, na maioria do ensino científico da Universidade Portuguesa distanciada da Reforma Pombalina, falta o prísino fervor da parte activa das aulas por arte dos alunos. Com Diogo Pacheco de Amorim podemos dizer hoje, em 1997, o que ele verificava passar-se em 1951: «nos nossos cursos, quem pensa, quem fala, quem tira conclusões, quem relaciona as doutrinas, quem sintetiza, quem resolve os problemas, quem discute as hipóteses, quem tudo faz e desfaz, é o mestre. O estudante não fala, ouve; não pensa, vê 
pensar». "Abri os Estatutos Pombalinos e lá vereis os remédios para todos esses males, concretamente descritos e sabiamente doseados"(20).

Com o prísino fervor da reforma pombalina do curso filosófico esperava o seu autor conseguir uma pleiade de homens preparados para a grande revolução industrial que se estava processando em todo o mundo culto e de que o país tinha grande necessidade. A ciência em Portugal precisa cultivar continuamente esse prísino fervor e a ele voltar sem cessar. Todos os apelos nesse sentido nunca serão demais. Rómulo de Carvalho, o homem cuja memória aqui queremos homenagear, foi um dos muitos homens de ciência que, em nossos dias, se não cansou em mostrar essa necessidade. A nossa homenagem é juntar o nosso apelo ao dele. As linhas que aqui ficam outra coisa não pretendem ser.

(20) Diogo Pacheco de Amorim, O. Cit., pg. 25; pg. 28. 